\title{
Important Aspects to Take Into Consideration When Administering Cytotoxic Chemotherapy. A Review
}

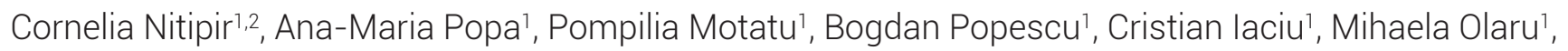
Anca-Mihaela Pantea Stoian', Razvan Hainarosie', Silviu Pituru', Maria Barbuํ,2

\begin{abstract}
Introduction: When discussing cytotoxic chemotherapy, the way the drugs are administered is as important as choosing the regimen. Several aspects like hyperhydration, emesis, the period of administration, diet and allergic reactions have to be taken into consideration. Method: Recent literature on these five main topics was revised. Most relevant data was collected and summarized in an attempt to familiarize any reader with this matter. Conclusion:These aspects are of utmost importance in reducing toxicity, thus enabling more extended treatment compliance, administration of effective doses and better oncological outcomes.
\end{abstract}

Keywords: cytotoxic chemotherapy, toxicity, administration.

\section{Rezumat}

Introducere: Când se ia în discuție chimioterapia citotoxică, modul de administrare al medicamentelor este la fel de important ca alegerea regimului de chimioterapie. Mai multe aspecte precum hiperhidratarea, emeza, perioada de administrare, dieta și reacțiile alergice trebuie luate în considerare. Metoda: Prezenta lucrare este un rezultat al analizei literaturii recente pe acest subiect și o sinteză a informației care să poată fi accesibilă oricărui cititor din domeniul medical. Concluzie: Aceste aspecte sunt foarte importante în a reduce toxicitatea la chimioterapie, permițând complianța mai bună la tratament, administrarea dozelor cu maximă eficiență și rezultate oncologice mai bune.

Cuvinte cheie: chimioterapie citotoxică, toxicitate, administrare.

\section{INTRODUCTION}

In the last decade, huge efforts have been made to optimize and personalize oncological treatment. Many novel therapies and better combinations of older ones have been implemented. Even if novelty is always exciting, one has take into consideration that the way a drug is administered is as important as the drug itself. The present review focuses on how the administration of several cancer drugs can minimize the toxicity they induce. It stresses that if enough importance is given to this aspect, patients can tolerate effective doses of treatment with better outcomes and have better quality of life.

\section{METHODS}

For the present paper, recent literature on five main topics including hyperhydration, emesis, the period of administration, diet and allergic reactions was revised. Most relevant data was collected in an attempt to familiarize any reader with this matter.
1 "Carol Davila"University of Medicine and Pharmacy, Bucharest, Romania

${ }^{2}$ Clinic of Medical Oncology, Elias Emergency University Hospital, Bucharest, Romania
Corresponding author:

Cristina Orlov, Clinic of Medical Oncology, Elias Emergency

University, Bucharest, Romania.

E-mail: orlov.cristina@gmail.com 


\section{HYPERHYDRATION}

Hyperhydration is defined as administering fluids to obtain $100 \mathrm{ml} / \mathrm{h}$ diuresis. It is a very effective way to avoid renal and urinary tract toxicity when using regimens that contain cisplatin, methotrexate, cyclophosphamide or ifosfamide. The first two can induce renal failure (both acute and chronic) by precipitating in the proximal and distal tubules in the kidney. Renal toxicity due to cisplatin usually results in azotemia, hypomagnesemia, hypokalemia ${ }^{1}$.

To avoid this, patients are supposed to take in at least $2000 \mathrm{ml}$ of fluids 12 hours before chemotherapy administration. During administration, hydration differs from one total dosage of cisplatin to another, as follows: for doses of cisplatin that exceed $80 \mathrm{mg} /$ $\mathrm{m}^{2} 4000 \mathrm{ml}$ over $4 \mathrm{~h}$ should be administered, for doses between 60 and $80 \mathrm{mg} / \mathrm{m}^{2}$, at least $2000 \mathrm{ml}$ over $2 \mathrm{~h}$ are necessary and for doses under $60 \mathrm{mg} / \mathrm{m}^{2} 1000 \mathrm{ml}$ over $1 \mathrm{~h}$. Adding electrolytes is useful, especially for the high doses. For example, in the case of more that $60 \mathrm{mg} / \mathrm{m}^{2}$ cisplatin is required, $20 \mathrm{mEqKCl} 1 \mathrm{~g} \mathrm{MgSO}$ and $30 \mathrm{~g}$ Mannitol should be added to hydration. When choosing hydration volume, we have to take in consideration whether the patient has preexistent kidney or cardiac failure, or if clinical signs of fluid retention exist ${ }^{2}$.

Renal methotrexate toxicity usually occurs at high doses (more that $1000 \mathrm{mg} / \mathrm{m}^{2}$ ). It is considered an emergency because this drug is mainly excreted through glomerular filtration and tubular secretion, so if renal failure occurs, high levels of serum methotrexate will persist, aggravating hematological and genitourinary toxicity. Hyperhydration and concomitant leucovorin (up to $1000 \mathrm{mg} / \mathrm{m}^{2}$ ) are strategies for avoiding this ${ }^{3}$.

However, in case of kidney failure, the two have to be continued, but also urine alkalization is necessary, which inhibits methotrexate precipitation in the renal tubules. The rest of the treatment includes alkaline intravenous fluids and glucarpidase (or carboxypeptidase-G2) if leucovorin is inefficient. The goal of the therapy is to lower the plasma level of methotrexate to less than $0.05 \mathrm{micromol} / \mathrm{m}^{2}$. In case of renal toxicity this should be monitored every 6 or 12 hours ${ }^{4,5}$.

When dealing with drugs that produce urothelial toxicity, like cyclophosphamide and ifosfamide the prevention strategy has some differences. Firstly, the probability for this toxicity to appear depends on the infusion rate, the metabolism rate, that is typical to every patient, urinary output, urinary frequency, concomitant exposure to other urothelial toxic drugs $\mathrm{s}^{6}$. Metabolism of the two alkylating agents results in compounds like acrolein, which are very irritant to the urothelial epithelium. These are the main reason for this toxicity. Usually, toxicity is clinically obvious, presenting as hemorrhagic cystitis, but cases with no macroscopic hematuria have been reported. Untreated, this condition leads to urinary bladder fibrosis, reflux or even urothelial carcinoma ${ }^{7}$.

Primary prophylaxis of bladder toxicity includes hyperhydrationand MESNA (usually administered with cyclophosphamide at doses more that $2 \mathrm{~g} / \mathrm{m}^{2}$, and always with iphosphamide). MESNA is a water-soluble compound that forms conjugates with acrolein, thus inactivating it. When administering high quantities of fluid with cyclophosphamide, one has to take into account fluid overload, given the fact that cyclophosphamide has an antidiuretic effect. The importance of frequent voidance of the bladder is unequivocal ${ }^{8}$.

The advantages of hyperhydration are undoubtely present, but what about its' risks? One has to take in consideration that with these high levels of fluid intake, even a patient with healthy kidneys and cardiac function will have an accumulation of water in the interstitial space and will be prone to electrolyte disturbances. The risk of pulmonary edema is high, especially in patients older than 65. Monitoring fluid balance is mandatory and several methods have been proposed. A recent study showed that weighing the patient before and some hours after treatment, as opposed to the complicated fluid output-input measuring is more precise in risk assessment ${ }^{1}$.

\section{NAUSEA AND EMESIS}

Chemotherapy-induced emesis and nausea are some of the most dose-limiting toxicities in cancer care. Incidence can be up to $90 \%$ in patients receiving highly emetogenic regimes without prophylaxis. Managing emesis and nausea has to be efficient, for the treatment to be administered at correct time intervals and at effective dosage. Chemotherapy regimens can be classified into low, moderate and highly emetogenic. Some agents have been recently re-classified, like carboplatin, for example. Carboplatin AUC 4 is considered now to have high emetogenic potential. Any dosage un$\operatorname{der} \mathrm{AUC}=4$ is moderately emetogenic. However, new agents have been added to the classification like atezolizumab , with low emetogenic potential or rucaparib with high emetogenic potential ${ }^{9}$.

Routine prophylaxis is mandatory for every category of the chemotherapy regimen. When administering highly emetogenic agents, NK (urokinase) antagonists 
should never be omitted, together with 5-HT3 RA (5hydroxytryptamine receptor antagonists) and steroids. Moderate emetic risk regimens imply prophylaxis with 5-HT3 RA and steroid. For low emetic risk agents, steroids, metoclopramide and prochlorperazine or 5 HT3 RA should be considered ${ }^{10}$.

However, there are several other aspects to take into consideration for emesis prophylaxis. 5-HT3 RA can increase the risk of $\mathrm{QT}$ prolongation, the dosage per day is usually limited (16 mg per day for ondansetron). Patients with cardiac risk factors should have their EKG monitored as clinically indicated. The most frequent adverse effects of these drugs are headache and constipation. The patient should be informed about them and instructed what action to take in case they appear. When 5-HT3 extended release methods are to be used and breakthrough emesis appears, the administration of an antiemetic drug with a different mechanism of action is indicated ${ }^{11}$.

Steroids are included in most of the emesis prophylaxis regimes so one should always keep in mind their adverse effects. Serum glucose values have to be monitored and should be administered with caution in patients with diabetes mellitus. Steroid-induced dyspepsia should be treated or prevented by $\mathrm{H} 2$ receptor antagonists or proton-pump inhibitors. When present, steroid-related insomnia should be treated ${ }^{12}$.

When dealing with breakthrough emesis one should always consider a drug with different mechanism of action than the ones used for prophylaxis. Olanzapine is a very efficient drug in this setting. Several new trials have proven its efficacy. It should not be used together with metoclopramide or haloperidol because they can cause cumulative extrapyramidal effects. Administration concomitant with phenothiazines is permitted, but should be done with care. The risk for falls should be considered for patients older than 70, or frail ones. Excessive sedation usually occurs within the first 2 days and improves over time, so there is no reason to lower the dose when this side effect appears, even in the elderly ${ }^{13,14}$.

\section{DURATION OF CHEMOTHERAPY ADMINISTRATION}

Duration is another important aspect of chemotherapy administration. Longer or shorter than recommended, administration regimens can influence toxicity decisively. Oxaliplatin, for example, should be administered in intermittent infusion in 5\% glucose solution over 3 hours. Administration should always be done before fluoropyrimidines. It should never be diluted in sodium chloride solutions. There is evidence that when pharyngolaryngeal dysesthesia appears, it can be ameliorated with longer administration (over 6 hours) ${ }^{15,16,17}$.

Paclitaxel is another drug with long administration time. It too should be administered over 3 hours and non-DEHP (a softner for polyvinyl chloride) sets must always be used. Usually, hypersensitivity reactions appear during the first 10 minutes of the first two cycles ${ }^{18}$. It must be stressed that the frequency of the hypersensitivity reactions is not related to the dosage or the duration of the administration. Correct premedication is the key to prevent this type of toxicity and it can lower the incidence from $40 \%$ to $2-3 \%{ }^{19}$.

On the other hand, there are drugs that have to be administered rapidly. The most conclusive example is vinorelbine, a vesicant agent, known for inducing infusion site reactions ${ }^{20}$. To prevent this, it should be administered in no more than 6 to 10 minutes, in continuous infusion ${ }^{21}$. After this, venous flushing with the same dilutant is mandatory. Placing warm pads on injection site seems to lower the risk of superficial thrombophlebitis $^{22}$.

Gemcitabine is also known to have higher toxicities when administered in longer periods of time. Infusion in more than one hour can increase toxicity due to the larger distribution volume of the $\mathrm{drug}^{23}$. There is some evidence that longer infusion produces better antitumoral effect. This is the reason why some regimens proposed a longer administration time, but at a fixed dose of $10 \mathrm{mg} / \mathrm{m} 2 / \mathrm{min}$. However, the usual administration time for gemcitabine is 30 minutes $^{24}$.

\section{DIET DURING CHEMOTHERAPY}

Diet during chemotherapy is another important matter. One has to take into account that chemotherapy induces neutropenia as one of its major side effects, making the patient susceptible to life-threatening infection. Fresh food and vegetables are a source of gramnegative bacilli that are harmless to an individual with normal immunity, but can be a threat to neutropenic patients. This fac led to the implementation of neutropenic or 'low bacterial diet'-LBD ${ }^{25}$. The efficacy of this dies in preventing febrile events during chemotherapy, patient hospital admissions and even positive blood cultures have been tested in a trial by DeMille et al. This trial included 23 patients who received chemotherapy and LBD and were monitored for 12 weeks. Study personnel called them at home and assessed adherence. Sixteen patients were compliant and 7 were non-com- 
pliant. Interestingly,fewer patients in the non-compliant group had a gram-negative febrile admission(14\% compared to $25 \%$ in the compliant group $)^{26}$. Even if this could be interpreted as evidence not to recommend low bacterial diet, it is clear that further research needs to be conducted. However, National Comprehensive Cancer Network (NCCN) guidelines on prevention and treatment of infectious complications do not mention the use of the neutropenic $\operatorname{diet}^{27}$. In the absence of clear evidence, when recommending this diet to the patient, one has to take into consideration many aspects like the general status of the patient, the chemotherapy regimen used and many other. Some questions are still under debate. They include: which patients benefit most from this option, which foods have to be included/excluded, what way to prepare foods is best?

\section{ALLERGIC REACTIONS TO CHEMOTHERAPY}

Moreover, allergic reactions to chemotherapy can interfere with the administration of the most efficient agents. Their incidence is different from drug to another and the time of onset is also particular. Carboplatin, for example, induces allergic reactions most often after the seventh cycle and most are moderate to severe ${ }^{28}$. To taxanes and particularly paclitaxel, however, patients are sensitized early in the course of treatment. Novel premedication protocols have managed to reduce the incidence of paclitaxel allergic reaction ${ }^{29}$. Usually, when facing this problem, prolonging the administration or supplementing premedication proves inefficient and

\section{References}

1. A Mank, A Semin-Goossens, J Lelie, P Bakker, R.Vos, Monitoring Hyperhydration during High-dose Chemotherapy: Body Weight or Fluid Imbalance? Acta Haematologica 2003; 109:163-168

2. BC Cancer Agency Genitourinary Tumour Systemic Policy Group. Administration of cisplatin in the outpatient setting. BC Cancer Agency; 8 June 2000

3. Joerger M, Huitema ADR, van den Bongard HJGD, et al. Determinants of the elimination of methotrexate and 7-hydroxymethotrexate following high-dose infusional therapy to cancer patients. Br J Clin Pharmacol 2005;62(1):71-80

4. Tamara Shenkier MD. Personal communication. Medical Oncologist, BC Cancer Agency; June 2006

5. Widemann BC, Hetherington ML, Murphy RF, et al. Carboxypeptidase- $G 2$ rescue in a patient with high dose methotrexate induced nephrotoxicity. Cancer 1995;76(3):521-6.

6. McEvoy GK. AHFS 2004 Drug Information. Bethesda, Maryland: American Society of Health-System Pharmacists, Inc.; 2004. p. 948-952.

7. Rose BD editor. Cyclophosphamide: Drug Information. www. uptodate.com ed. Waltham, Massachusetts: UpToDate; 2005. one might think that changing the line of therapy is a must. Rapid desensitization is an efficient method to avoid this. It consists of progressively upgrading doses during the same administration. For example, the regimen can start with administering $1 \%$ of the total dose during 30 minutes, then $10 \%$ in a fixed amount of time, then the rest. Regimens have to be established by the allergist together with the treating physician. The treatment is at first administered in an ICU unit, with close observation. If the first administration was without events, outpatient regimen could be a valid option. There are some effective ways to foresee an allergic reaction, like the skin test $\mathrm{t}^{30}$. This is most useful with carboplatin, where testing after the sixth administration is often positive. This is a way of preventing the almost imminent allergic event, by initiating the desensitizing regimen before the reaction appears ${ }^{31}$. This strategy cannot be applied in the case of paclitaxel. Skin tests are not significant in this setting probably because the reaction is not $\mathrm{IgE}$-mediated. However, not all allergic reactions to all types of chemotherapy agents are amendable to desensitization. When experiencing an event like this, correctly assessing it is of utmost importance ${ }^{30}$.

\section{CONCLUSION}

To conclude, this review summarizes the most important aspects to consider when administrating chemotherapy and stresses their importance in reducing toxicity, thus enabling more extended treatment compliance, administration of effective doses and better outcomes.

8. West NJ. Prevention and treatment of hemorrhagic cystitis. Pharmacotherapy.1997;17(4):696-706

9. Grunberg SM, Warr D, Gralla RJ, et al. Evaluation of new antiemetic agents and definition of antineoplastic agent emetogenicity-state of the art. Support Care Cancer 2010;19:S43-47

10. Herrstedt J. Antiemetics: an update and the MASCC guidelines applied in clinical practice. Nat Clin Pract Oncol 2008; 5:32-43

11. Rojas C, Li Y, ZhangJ, et al. The antiemetic 5-HT3 receptor antagonist Palonosetron inhibits substance P mediated responses in vitro and in vivo. J Pharmacol Exp Ther 2010;335:362-368.

12. Grunberg SM, Dugan M, Muss $H$, et al. Effectiveness of a single day three-drug regimen of dexametazone, palonosetron and aprepitant for the prevention of acute and delayed nausea and vomiting cause by moderatelly emetogenic chemotherapy. Support care Cancer 2009; 17:589-594.

13. Navari RM, Nagy CK, Gray SE. The use of olanzapine versus metoclopramide for the treatment of breackthrough chemotherapy induced nausea and vomiting in patients receiving highly emetogenic chemotherapy. Support Care Cancer 2013; 21:16551663. 
14. Hashimoto $H$, Yanai T, Nagashima $K$, et al. A double blind randomised phase 2 study of $10 \mathrm{mg}$ versus $5 \mathrm{mg}$ olanzapine for emesis induced by highly emetogenic chemotherapy with cisplatin [abstract]. J Clin Oncology 2016; 34 abstract 10111.

15. Wiseman LR, Adkins JC, Plosker GL, et al. Oxaliplatin: a review of its use in the management of metastatic colorectal cancer. Drugs \& Aging 1999;14(6):459-75

16. Freyer $G$, Bossard $N$, Romestaing $P$, et al. Oxaliplatin (OXA), 5-fluorouracil (5FU), L-folinic acid (FA) and concomitant irradiation in patients with rectal cancer: A phase 1 study. Proceedings of the American Society of Clinical Oncology 2000;19:260aabstract 1012

17. Graham MA, Lockwood GF, Greenslade D, et al. Clinical pharmacokinetics of oxaliplatin: a critical review. Clinical Cancer Research 2000;6(4):1205-18.

18. Biolyse. PACLITAXEL FOR INJECTION ${ }^{\circledR}$ product monograph. St. Catherines, Ontario; 2 December 2005.

19. Kintzel PE. Prophylaxis for paclitaxel hypersensitivity reactions. Ann Pharmacother 2001;35(9):1114-1117

20. Gregory RK, Smith IE. Vinorelbine--a clinical review. Br J Cancer 2000;82(12):1907-1913

21. Toussaint C, Izzo J, Spielmann M, et al. Phase I/II trial of continuous infusion vinorelbine for advanced breast cancer. J Clin Oncol 1994;12(10):2102-2112.

22. Ginopoulos P, Mastronikolis NS, Karana A, et al. Use of dexamethasone in the management of phlebitis caused by intravenous administration of vinorelbine (navelbine). Medical Science Research 1998;26(6):397-398.
23. Eli Lilly Canada. GEMZAR ${ }^{\circledR}$ product monograph. Toronto, Canada; 28 April 2014

24. Veltkamp SA, Beijnen JH, Schellens JHM. Prolonged versus standard gemcitabine infusion: translation of molecular pharmacology to new treatment strategy. Oncologist 2008;13(3): 261-276.

25. Moody K, Charlson ME, Finlay J. The neutropenic diet: what's the evidence? J Pediatr Hematol Oncol 2002;24:717-721

26. DeMille $D$, Deming $P$, Lupinacci $P$ et al. The effect of the neutropenic diet in the outpatient setting: a pilot study. Oncol Nurs Forum 2006;33:337-343.

27. The National Comprehensive Cancer Network (NCCN) 2017 prevention and treatment of infectious complications

28. Markman M, Kennedy A, Webster K, Elson P, Peterson G, Kulp B, et al. Clinical features of hypersensitivity reactions to carboplatin. J Clin Oncol 1999;17:1141-5

29. Markman M, Kennedy A, Webster K, Kulp B, Peterson G, Belinson J. Paclitaxel associated hypersensitivity reactions: experience of the gynecological oncology program of the Cleveland Clinic Cancer Center. J Clin Oncol 2000;18:102-5

30. M.C. Castells, N.M.Tennant, D.E. Sloane Hypersensitivity reactions to chemotherapy: Outcomes and safety of rapid desensitization in 413 cases. 2008 American Academy of Allergy, Asthma \& Immunology doi:10.1016/j.jaci.2008.02.044

31. Choi J, Harnett P, Fulcher DA. Carboplatin desensitization. Ann Allergy Asthma Immunol 2004;93:137-41 